\title{
Assessment of Fertility and Reproductive Toxicity in Adult Female Mice after Long-Term Exposure to Pueraria mirifica Herb
}

\author{
Sukanya JAROENPORN ${ }^{1-3)}$, Suchinda MALAIVIJITNOND ${ }^{2}$, \\ Kingkaew WATTANASIRMKIT ${ }^{2)}$, Gen WATANABE ${ }^{3,4)}$, Kazuyoshi TAYA ${ }^{3,4)}$ and \\ Wichai CHERDSHEWASART ${ }^{2)}$
}

\begin{abstract}
1)Interdepartment of Physiology, Faculty of Graduate School, Chulalongkorn University, Bangkok 10330, ${ }^{2)}$ Primate Research Unit, Department of Biology, Faculty of Science, Chulalongkorn University, Bangkok 10330, Thailand, ${ }^{3)}$ Department of Basic Veterinary Science, The United Graduated School of Veterinary Sciences, Gifu University, Gifu 501-1193 and ${ }^{4)}$ Laboratory of Veterinary Physiology, Department of Veterinary Medicine, Faculty of Agriculture, Tokyo University of Agriculture and Technology, Tokyo 183-8509, Japan
\end{abstract}

\begin{abstract}
The present study investigated the effects of long-term administration of Pueraria mirifica (PM) at non-toxic doses on the ovarian function and fertility of adult female mice based on evaluation of hematological and biochemical parameters [1]. Female mice were divided into 4 groups (36 mice/ group). Groups 1-3 were orally treated with a dose of 0 (PM-0), 10 (PM-10) or $100 \mathrm{mg} / \mathrm{kg} \mathrm{BW/day}$ PM (PM-100), and group 4 was subcutaneously injected with $200 \mu \mathrm{g} / \mathrm{kg} \mathrm{BW} /$ day of synthetic estrogen diethylstilbestrol (DES). The treatment schedule was separated into treatment and post-treatment periods. The duration of each period was 8 weeks. The PM-10 mice exhibited regular estrous cycles, while the PM-100 and DES treatments induced prolonged estrous cycles. Although no changes were observed in the uterus and ovary weights of the mice after the PM-100 and DES treatments, hyperplasia of the uterine endothelium and a decrease in the number of growing ovarian follicles were detected. The changes in the ovarian histologies of the PM-100 and DES mice were related to reductions in the levels of $\mathrm{LH}$ and $\mathrm{FSH}$, which subsequently caused a decrease in mating efficiency. Once the PM mice were able to copulate, they were capable of successfully becoming pregnant and mothering offspring. No abnormalities were observed in the external morphologies and reproductive organ weights of the 50-day-old offspring. In conclusion, our results suggest that long-term exposure to $100 \mathrm{mg} / \mathrm{kg}$ BW of PM has adverse effects on the mating efficiency and reproduction of adult female mice and that administration of $10 \mathrm{mg} / \mathrm{kg}$ BW of PM does not induce any changes in the hypothalamic-pituitary-ovarian-uterine axis.
\end{abstract}

Key words: Diethylstilbestrol (DES), Female mice, Fertility, Phytoestrogens, Pueraria mirifica

(J. Reprod. Dev. 53: 995-1005, 2007)

$\mathbf{T}$ raditional use of medicinal plants to treat different sorts of diseases, such as reproductive and

Accepted for publication: May 7, 2007

Published online: June 22, 2007

Correspondence: S. Malaivijitnond

(e-mail: Suchinda.m@chula.ac.th) fertility-related diseases, is widespread throughout the world, especially in Asian countries. In fact, Dangui in China, Dangui and Kudzu in Korea, Auravedi in India and Jamu in Indonesia all traditionally use medicinal plants for the purposes above. Plants containing phytoestrogens are of 
long-term interest. Pueraria mirifica (PM) is an indigenous herb and known in Thai as White Kwao Krua. It belongs to the family Leguminosae, subfamily Papilionoideae [2]. Its tuberous root is known to contain at least the following 13 phytoestrogens: daidzin, daidzein, genistin, genistein, deoxymiroestrol, miroestrol, $\beta$-sitosterol, stigmasterol, coumestrol, puerarin, mirificoumestan, kwakhurin and mirificin [3-5]. Thus, verification of the estrogenic effects of $P$. mirifica in various species of experimental animals has been conducted, especially in the recent years.

The estrogenic activity of miroestrol isolated from PM was first determined in female rats $[3,6]$. Miroestrol increases uterus weight, vaginal growth and the amount of vaginal fluid in intact rats and induces mammogenic effects in ovariectomized rats. Feeding PM powder suspended in water to ovariectomized rats induces proliferation of the vaginal epithelium and uterus endometrium and reduces the levels of serum follicle-stimulating hormone (FSH) and luteinizing hormone (LH) $[7,8]$. Reduction of the levels of FSH and LH has also been observed in adult cyclic and aged menopausal female monkeys [9-12]. PM suppresses folliculogenesis and ovulation in adult cyclic female monkeys after a single or long-term feeding $[9,10]$. Intake of crude $P$. mirifica powder can relieve climacteric symptoms, such as hot flashes, frustration, sleep disorders and skin dryness in post-menopausal women [13].

Because of its popular use, the toxicity of PM has also been evaluated for various organs, such as the liver, spleen and kidney. Evaluation of powder and extract from the plant has shown that it has no toxic effects on the eyes and skin of rodents and rabbits [14]; on the other hand, it can stimulate reddening of sex skin in aged menopausal monkeys [15]. The toxicity of PM at doses higher than 100 $\mathrm{mg} / \mathrm{kg} \mathrm{BW}$ has also been tested in rats $[1,16]$. It causes anemia symptoms and mutagenicity in subjects. Mutagenicity has also been observed for doses higher than $100 \mathrm{mg} / \mathrm{kg}$ BW [16]. In a previous study, acute and subchronic toxicity tests in rats using doses of PM of 10 and $100 \mathrm{mg} / \mathrm{kg} \mathrm{BW/}$ day did not result in any abnormalities of hematological and biochemical parameters or any changes in the histopathology of the metabolic organs [1]. The authors of that study suggested that doses of 10 and $100 \mathrm{mg} / \mathrm{kg} \mathrm{BW/day} \mathrm{of} \mathrm{PM} \mathrm{are} \mathrm{safe} \mathrm{for} \mathrm{human}$ consumption on a $\mathrm{kg}$ BW basis. Without evaluation of the toxicity of PM in relation to the reproductive system and fertility, these results should not be considered sufficient to suggest that general use of PM is safe. Thus, the aim of the present study was to investigate this in adult female mice. For this study, we conducted a comparative investigation to determine whether PM can affect the fertility and reproductive system of female mice after long-term treatment at doses of 10 and $100 \mathrm{mg} / \mathrm{kg}$ BW/day and to examine the malformations in F1 offspring delivered by the PM-treated mothers.

Diethylstilbestrol (DES) was used as a positive control in order to clarify whether PM has effects similar to those of estrogen. DES is a synthetic estrogen that has a higher binding affinity to estrogen receptor (ER) both the $\alpha$ and $\beta$ subtypes, and a higher potency of estrogenic biological activity than estradiol $[17,18]$. Our previous study found that a dose of $200 \mu \mathrm{g} / \mathrm{kg}$ BW/day of DES reduced the weights of the testes, epididymides and seminal vesicles of adult male mice after 8 weeks of treatment. Furthermore, the DES-treated mice had no spermatozoa in their seminiferous tubules and epididymides and had reduced levels of LH, FSH and testosterone. None of the DES-treated mice mated with or impregnated any female mice, and therefore a dose of $200 \mu \mathrm{g} / \mathrm{kg} \mathrm{BW} /$ day of DES was chosen for the present study [19].

\section{Materials and Methods}

\section{Plant materials}

Pueraria mirifica cultivar Wichai-III was collected in Chiang Mai Province, Northern Thailand. The voucher herbarium specimen of the PM (no. BCU 11045) was deposited at the Herbarium of the Department of Botany, Faculty of Science, Chulalongkorn University, Bangkok, Thailand. The constituent phytoestrogens of the Wichai-III cultivar, as determined by HPLC technique, have been described previously [7]. The tuberous roots used throughout this study were from the same lot. The roots were sliced and dried at 70-80 C and pulverized in a mortar. The powder was filtered through a 100-mesh size and stored in desiccators until used. The PM powder was suspended in sterile distilled water before use.

\section{Chemicals}

Diethylstilbestrol (DES) and corn oil were 
obtained from Sigma-Aldrich (St. Louis, MO, USA). DES was diluted with corn oil and mixed vigorously prior use.

\section{Animals}

Adult ICR mice, 50-60 days old and weighing 25-27 g, were obtained from the National Laboratory Animal Center, Mahidol University, Nakhon Pathom, Thailand. They were housed 5 animals/ cage in a room with controlled lighting (lights on 0600-2000 h) and temperature (25 $\pm 1 \mathrm{C})$ at the Primate Research Unit, Department of Biology, Faculty of Science, Chulalongkorn University. The animals were fed a rat diet (Pokphand Animal Feed, Bangkok, Thailand) and water ad libitum. They were habituated by handling regularly for 2 weeks before the experiments. They were checked daily for estrous cyclicity by examining their vaginal cytology. The mice selected had at least 3 consecutive regular estrous cycles of 4-5 days in length before the onset of this study. All experiments were performed between $0800-1100 \mathrm{~h}$. The experimental protocol was approved by the Animal Ethical Committee in accordance with the Guide for Care and Use of Laboratory Animals prepared by Chulalongkorn University, Bangkok, Thailand.

\section{Experimental design}

The adult female mice were divided into 4 groups (36 mice/group). Group 1-3 mice were orally treated with 0,10 or $100 \mathrm{mg} / \mathrm{kg} \mathrm{BW/day} \mathrm{of}$ PM suspended in $0.2 \mathrm{ml}$ distilled water (PM-0, PM10 and PM-100, respectively). Group 4 mice were subcutaneously injected with $0.2 \mathrm{ml}$ of $200 \mu \mathrm{g} / \mathrm{kg}$ $\mathrm{BW} /$ day of synthetic estrogen DES. The body weights of the mice were measured each day and were used to adjust the concentration of PM and DES. The treatment schedule was separated into treatment and post-treatment periods. The duration of each period was 8 weeks. Blood samples were collected from the mice for the LH and FSH assays by cardiac puncture during the proestrous stage if they exhibited a regular estrous cycles or at any stages if they exhibited an irregular estrous cycles; the samples were collected in 4-week intervals for a total of 5 samples (at 0, 4, 8, 12 and 16 weeks). Six female mice were paired with the fertile male mice ( 3 females per male) after collection of each blood sample, except at 0 weeks. After mating, the female mice were removed from the treatment schedule. Six mice from each group were selected and decapitated after euthanization at the end of the treatment period or at the end of posttreatment period; 12 mice in total. After necropsy, ovaries and uteri were dissected, weighed and preserved in $10 \%$ formalin buffer for histological examination.

The female mice removed after mating were observed for pregnancy and delivery. The copulation rates, pregnancy rates and numbers of offspring delivered and malformations were examined. The number of litters was counted, and the offspring were reared until they reached 50 days old. The offspring were weaned at 21 days of age. External morphologies, such as hair loss and abnormalities in ears, fingers, toes and tails, were observed. The offspring were decapitated after euthanizing at 50 days of age; their gonads and accessory genital glands were then dissected and weighed.

\section{Vaginal smear checks}

Vaginal smears were checked daily between $0800-0900 \mathrm{~h}$ as described previously [8]. The vaginal epithelium cells were examined under a microscope and classified into the following 3 types: leukocyte cells, nucleated cells and cornified cells. The estrous cycle was categorized into the following 3 stages based on cell type: proestrus (P), estrus (E) and diestrus (D). Cornified cells were used as an indicator of vaginal proliferation.

\section{Mating studies}

Six female mice were paired with the fertile male mice ( 3 females per male) for 1 night from 1800 $0600 \mathrm{~h}$ every 4 weeks during the experimental period. The criteria for selection of the females were as follows: 1) proestrous mice were chosen if the female mice exhibited regular estrous cycles and 2) mice at any stages of the estrous cycle were chosen if the female mice exhibited irregular estrous cycles. Positive mating was verified either by the presence of copulation or the occurrence of sperm as determined by vaginal smears. The day of positive mating was considered to be the first day of pregnancy. The mated female mice were observed for signs of pregnancy, such as nest building, and delivery after day 20.

\section{Hormonal analysis}

The concentrations of serum FSH and LH were measured using NIDDK kits for rat FSH and LH. 
The iodination preparations were NIDDK-rat FSHI-5 and rat LH-I-5. The antisera were anti-rat FSHS11 and anti-rat LH-S11. The results obtained were expressed in terms of the rat FSH-RP-2 and LH-RP3 reference standards.

To minimize interassay variation, all samples from each group were run in a single assay for each hormone. The intra-assay coefficients of variation for LH and FSH were 2.24 and 6.34\%, respectively.

\section{Histological examination}

After the reproductive organs were fixed overnight in $10 \%$ formalin buffer, the tissues were dehydrated in a graded series of ethanol and cleared in xylene. They were then embedded and blocked in paraffin, cut into $5-\mu \mathrm{m}$ sections and stained with hematoxylin and eosin. Permanent preparations of all collected organs were histologically examined and photographed using a camera (Nikon, Tokyo, Japan) mounted on a microscope (Olympus, Tokyo, Japan).

\section{Statistical analysis}

The results were expressed as means \pm SEM. The copulation rate was calculated as the number of copulated females per the total number of females used $\times 100$. The pregnancy rate was calculated as the number of pregnant females per the number of copulated females $\times 100$. Statistical analyses were performed using Statistical Package for the Social Sciences (SPSS) program version 11. The pairedsample $t$-test was used to compare organ weights between the end of the treatment period and the end of the post-treatment period for each group. Comparisons between the control and treatment groups were conducted by one-way analysis of variance (ANOVA) with the factorial or repeated measures designs and post-hoc testing with the least significant difference (LSD) test. $P$ values of less than 0.05 were considered to be statistically significant.

\section{Results}

\section{General appearance}

During this experiment, no deaths or any other clinical signs of toxicity (hair loss, drowsiness or weakness) were observed for the female mice.

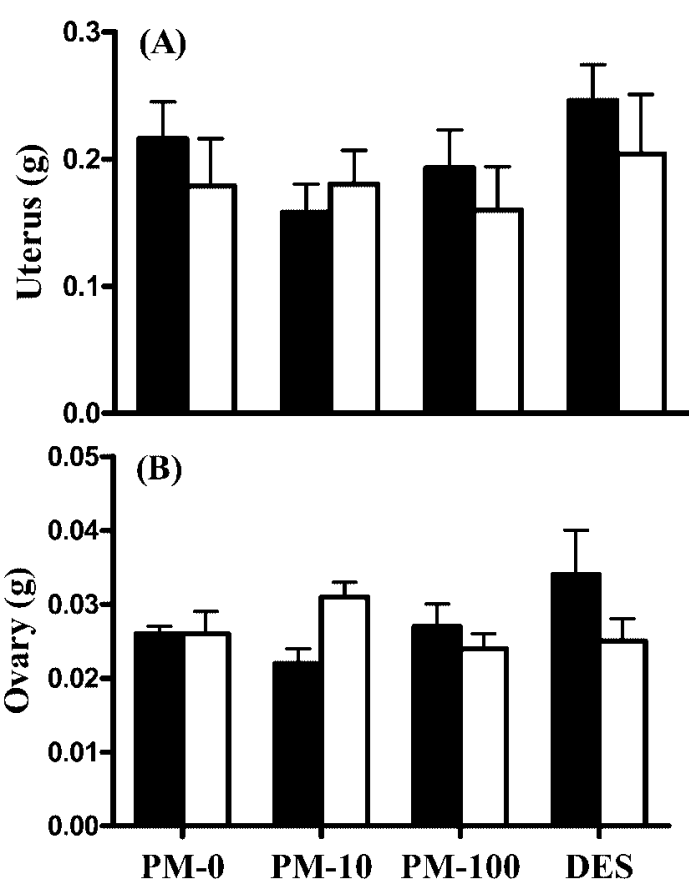

Fig. 1. Weights of the uteri (A) and ovaries (B) of female mice treated with 0,10 or $100 \mathrm{mg} / \mathrm{kg}$ BW/day of Pueraria mirifica (PM-0, PM-10 and PM-100, respectively) or $200 \mu \mathrm{g} / \mathrm{kg} \mathrm{BW} /$ day of diethylstilbestrol (DES) at the end of treatment period ( $\square$ ) and at the end of posttreatment period $(\square)$. Each value represents the mean \pm SEM of six animals. Since the PM-0- and PM10-treated mice exhibited regular estrous cycles, the mice were decapitated during the proestrous stage. The PM-100- and DES-treated mice exhibited irregular estrous cycles and were decapitated during any stage of the estrous cycle.

\section{Weights of ovaries and uteri}

There were no significant differences in the weights of the uteri and ovaries between the PM-0 group and the PM-10, PM-100 and DES groups, respectively (Fig. 1).

\section{Vaginal cytology}

Administration of PM-10 did not influence vaginal cornification, and the PM-10 female mice exhibited regular estrous cycles of 4-5 days throughout the experimental period that were the same as those of the PM-0 mice (Fig. 2). Treatment with PM-100 and DES induced cornification of the vaginal epithelium as early as the second day of treatment and maintained the cornified cells (or persistent estrus) until the last day of the treatment period. The mice recovered from treatment and returned to regular estrous cycles 3-4 days after 
PM-0

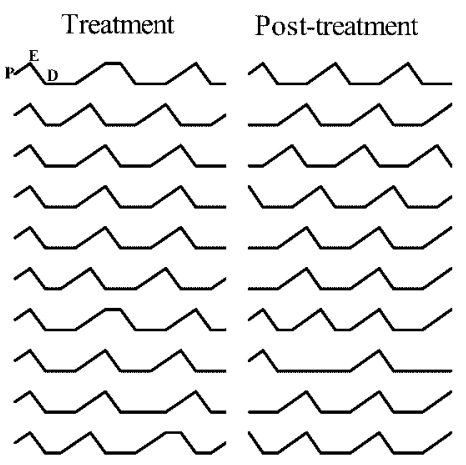

\section{PM-100}

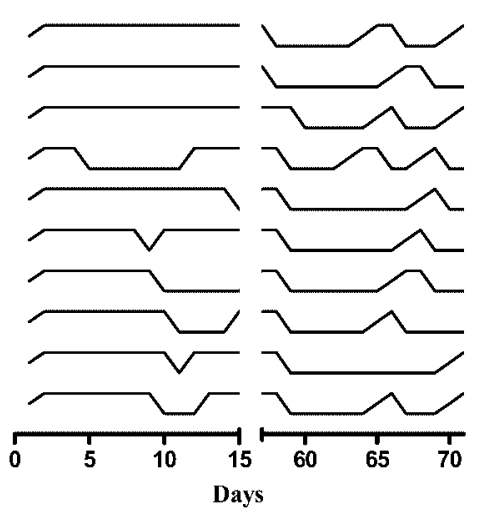

PM-10
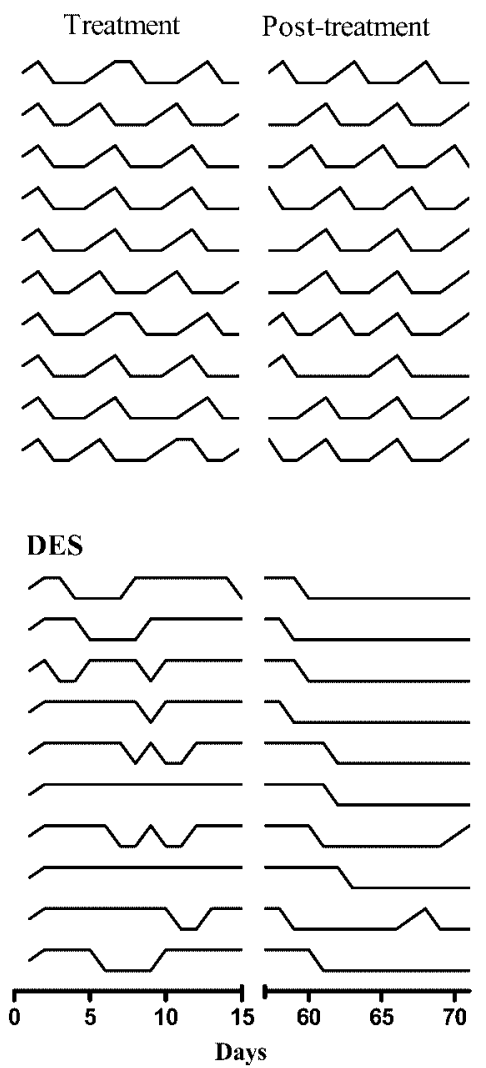

Fig. 2. Daily monitoring of vaginal cytology for female mice treated with 0 , 10 or $100 \mathrm{mg} / \mathrm{kg} \mathrm{BW/day} \mathrm{of} \mathrm{Puer-}$ aria mirifica (PM-0, PM-10 and PM100 , respectively) or $200 \mu \mathrm{g} / \mathrm{kg}$ BW/day of diethylstilbestrol (DES) during the treatment and posttreatment periods. The first two weeks of data of each period are shown. Each line represents an individual animal. P: proestrus. E: estrus. D: diestrus. The 10 subjects shown for each group are representative of the 36 mice for the treatment period and 12 mice for the post-treatment period; however, the data for the treatment and posttreatment periods (lines at the same horizontal level) came from the same individual mice. withdrawal of PM-100. In contrast, vaginal cornification lasted for 4-8 days after DES withdrawal, and the mice did not recover or return to a regular estrous cycle until the end of experimental period; only leukocyte cells were found.

\section{Histology of uteri and ovaries}

The uterine histology of the PM-10 group did not differ from that of the PM- 0 group during the treatment and post-treatment periods (Fig. 3A and B). In contrast, the uteri of the PM-100- and DEStreated mice contained a thicker endometrium and more dilated uterine glands than those of the PM-0 group (Fig. $3 C_{1}$ and $D_{1}$ ). The uterine glands of the mice treated with DES also accumulated a lot of secretory material. However, these histological alterations recovered within 8 weeks of withdrawal of PM and DES (Fig. $3 C_{2}$ and $3 \mathrm{D}_{2}$ ).

There were no morphological differences between the ovaries of the PM-10 group and those of the PM-0 group (Fig. 3F). Edema of ovarian interstitial tissues was observed in the PM-100 and
DES groups. A decrease in primary, secondary and Graafian follicles was also observed in the ovaries of the PM-100- and DES-treated mice (Fig. 3G $\mathrm{G}_{1}$ ). In addition, the ovaries of the DES-treated mice contained many atretic follicles with some picnotic nuclei (Fig. $\left.3 \mathrm{H}_{1}\right)$. However, all these morphological changes in the ovary recovered within 8 weeks after withdrawal of PM-100 and DES (Fig. $3 \mathrm{G}_{2}$ and $\mathrm{H}_{2}$ ).

\section{Gonadotropin levels}

The serum LH levels of the PM-10 group were significantly higher $(\mathrm{P}<0.05)$ than those of the $\mathrm{PM}-0$ group at 8 weeks during the treatment and posttreatment periods, respectively (Fig. 4A). Conversely, the serum LH levels of the PM-100 group were significantly decreased $(\mathrm{P}<0.05)$ at 8 weeks during the treatment period. Significant suppression $(\mathrm{P}<0.05)$ of the serum LH level was also observed in the DES group throughout the 8 weeks of the treatment period, and recovery was observed within 4 weeks of DES withdrawal. 


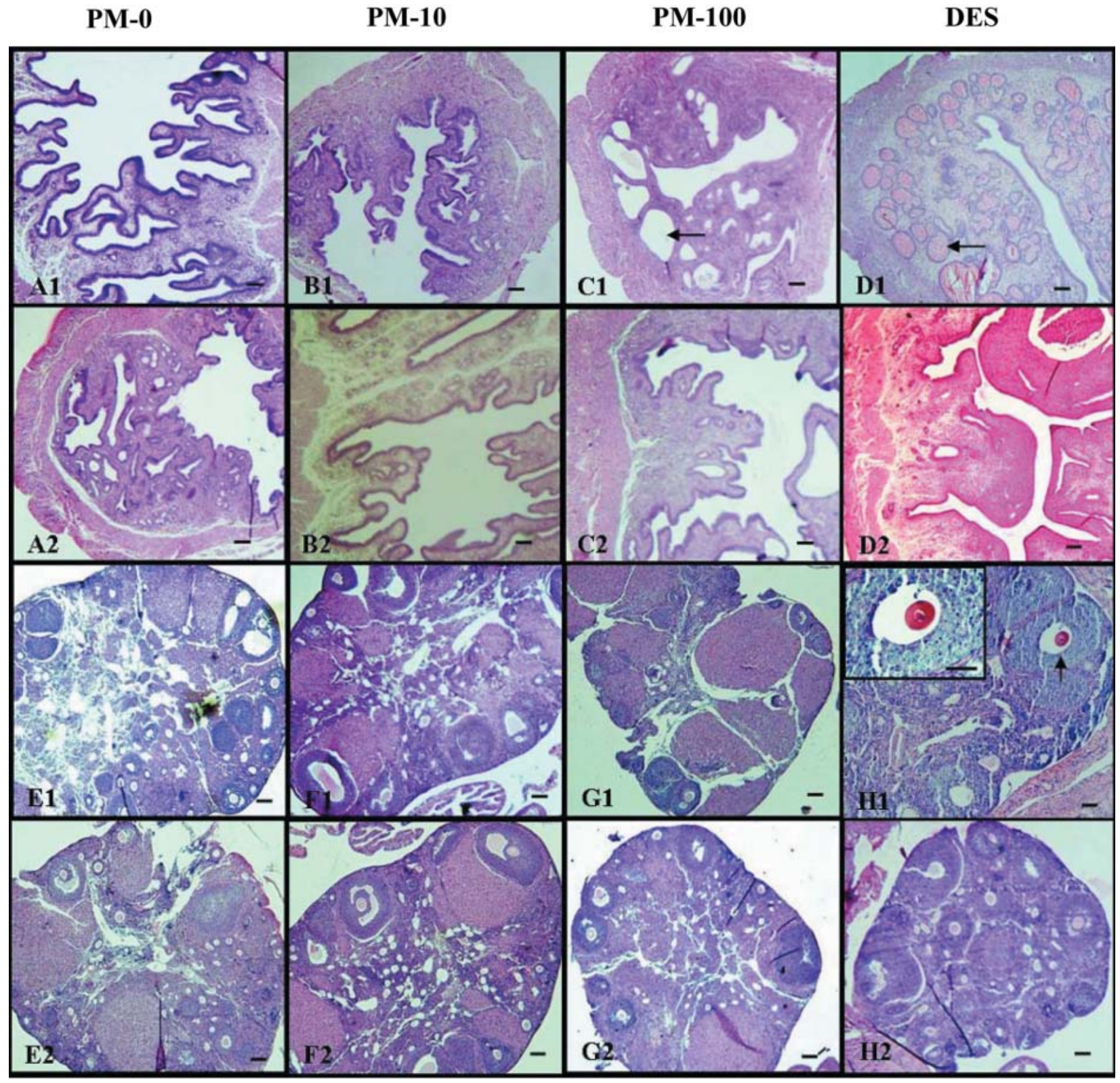

Fig. 3. Histological comparisons of uteri (A-D) and ovaries $(\mathrm{E}-\mathrm{H})$ at the end of the treatment period (1) and at the end of the posttreatment period (2) for mice treated with 0,10 or $100 \mathrm{mg} / \mathrm{kg}$ BW/day of Pueraria mirifica (PM-0, PM-10 and PM-100, respectively) or $200 \mu \mathrm{g} / \mathrm{kg} \mathrm{BW} /$ day of diethylstilbestrol (DES). No remarkable lesions were observed in the uteri or ovaries of the PM-10-treated mice. The mice treated with PM-100 and DES exhibited thicker endometria, dilated uterine glands (arrows) and decreased numbers of ovarian growing follicles. The mice treated with DES also exhibited the atretic follicles (arrows) with some picnotic nuclei in the ovary. Hematoxylin and Eosin staining (Scale bars=50 $\mu \mathrm{m}$ ). The day of decapitation was stated in Fig. 1.

The serum FSH levels of the PM-0 group fluctuated throughout the experimental period (Fig. 4B). The fluctuation tended toward increase during the treatment period. Thus, significantly low serum FSH levels were observed at 8 weeks during the treatment period in the PM-10, PM-100 and DES groups $(\mathrm{P}<0.01)$ compared with the $\mathrm{PM}-0$ group.

\section{Fertility}

The copulation rate of the female mice treated 
(A)

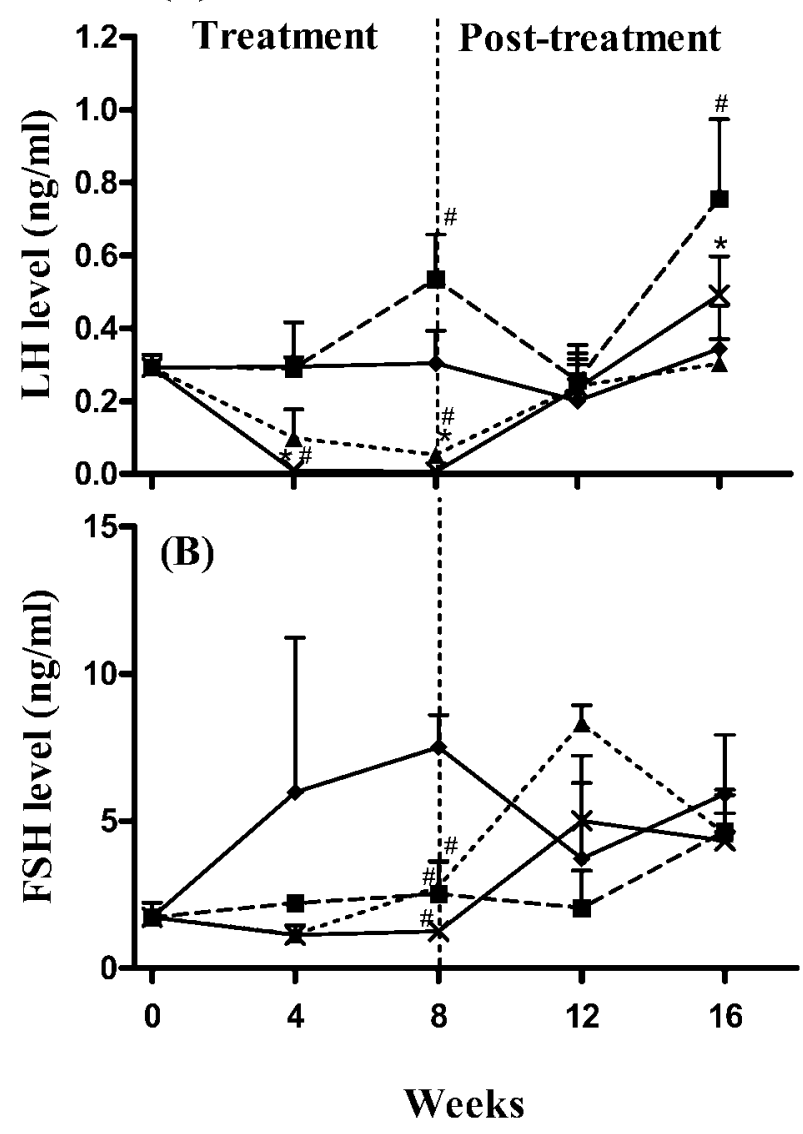

Fig. 4. Serum LH (A) and FSH (B) levels of female mice treated with 0 ( $\neg$; PM-0), 10 ( $\rightarrow$ - ; PM-10) or 100 (-A-; PM-100) mg/kg BW/day of Pueraria mirifica or diethylstilbestrol ( $*$;DES) during the treatment and post-treatment periods. ${ }^{*} \mathrm{P}<0.05$ vs. the basal level at 0 weeks. ${ }^{\# P}<0.05$ vs. PM-0. Each value represents the mean \pm SEM of six animals. The day of decapitation was stated in Fig. 1.

with PM-10 tended to be similar to that of the PM-0 group (Table 1). Although the copulation rate of the PM-10 mice was higher than that of the PM-0 group at 8 weeks during the treatment period ( 83.33 vs. $50.00 \%$ for PM-10 vs. PM-0), the results for these two groups at this time point could not be compared because the copulation rate of the PM-0 mice at this time point was abnormally lower than at other time points. One explanation for the low pregnancy rate for the PM-0 mice is that all of the tested female mice used in this study were virgin females, which means that none had experienced pregnancy before, and only six individuals were tested during each period.

In contrast, PM-100 drastically reduced the copulation rate at 4 weeks $(33.33 \%)$ and 8 weeks $(0 \%)$ during the treatment period. However, the reductions recovered within 4 weeks $(66.67 \%)$ of PM-100 withdrawal. Few of the DES-treated mice, only 1 and 2 mice at 4 and 8 weeks during the treatment period, respectively, mated with the untreated male mouse, and absolutely no pregnancies were observed. Although the DES treatment was stopped for 8 weeks, only 1 of the 6 mice $(16.67 \%)$ recovered and accepted mating from a male mouse and became pregnant at 4 and 8 weeks during the post-treatment period, respectively. All PM-10 and PM-100 mice became pregnant $(100 \%)$ and delivered offspring once they were able to copulate with a male mouse, except for the PM-100 mice at 8 weeks during the post-treatment period, which had a pregnancy rate of $75 \%$. On the other hand, the pregnancy rate of the PM-0 group varied from $33.33-80.00 \%$ during both the treatment and posttreatment period; the pregnancy rate of the DES group during the treatment period was $0 \%$.

\section{Average number of offspring and relative reproductive organs weights of litters}

The number of offspring mothered by the PMand DES-treated mice corresponded to the observed copulation and pregnancy rate. The number of offspring mothered by the PM-10-treated mice was not different than that of the PM-0 mothers throughout the experimental period, even though the copulation and pregnancy rates of the PM-10 group were higher at 8 weeks during the treatment period (Table 2). The PM-100 group had fewer offspring at 4 weeks and no offspring at 8 weeks during the treatment period. However, the number of offspring was similar to that of the PM-0 group thereafter. No pregnancies were observed in the DES-treated mice, and no offspring were produced by this group. As mentioned previously, 1 of the 6 mice receiving the DES treatment became pregnant during the post-treatment period and produced offspring. However, the number of offspring delivered by the DES-treated mothers was quite low compared with those of the PM-treated mice (ranging between 8 to 12 offspring).

No external morphological abnormalities were found in the offspring mothered by the PM- and DES-treated mice. The relative organ weights of the ovaries and uteri of the female pups and the tes- 
Table 1. Numbers of copulations and pregnancy rates for female mice treated with 0,10 or $100 \mathrm{mg} / \mathrm{kg}$ BW/day of Pueraria mirifica (PM-0, PM-10 and PM-100, respectively) or $200 \mu \mathrm{g} / \mathrm{kg}$ BW/day of diethylstilbestrol (DES) after mating with a fertile male mouse

\begin{tabular}{lcccccccc}
\hline Group & $\begin{array}{c}\text { At } 4 \text { weeks during } \\
\text { the treatment period } \\
(\mathrm{n}=6)\end{array}$ & \begin{tabular}{c}
$\begin{array}{c}\text { At } 8 \text { weeks during the } \\
\text { treatment period } \\
(\mathrm{n}=6)\end{array}$ \\
\cline { 2 - 10 }
\end{tabular} & $\begin{array}{c}\text { Copulations } \\
\text { Cregnancies }\end{array}$ & $\begin{array}{c}\text { Copulations } \\
\text { post-treatment period } \\
(\mathrm{n}=6)\end{array}$ & $\begin{array}{c}\text { Pregnancies } \\
\text { Copulations }\end{array}$ & $\begin{array}{c}\text { Pregnancies } \\
\text { post-treatment period } \\
(\mathrm{n}=6)\end{array}$ & $\begin{array}{c}\text { Copulations } \\
\text { Pregnancies }\end{array}$ \\
\hline PM-0 & 5 & 4 & 3 & 1 & 4 & 3 & 5 & 4 \\
& $83.33 \% *$ & $80.00 \%$ & $50.00 \%$ & $33.33 \%$ & $66.67 \%$ & $75.00 \%$ & $83.33 \%$ & $80.00 \%$ \\
PM-10 & 4 & 4 & 5 & 5 & 3 & 3 & 3 & $100 \%$ \\
& $66.67 \%$ & $100 \%$ & $83.33 \%$ & $100 \%$ & $50.00 \%$ & $100 \%$ & $50.00 \%$ & $100 \%$ \\
PM-100 & 2 & 2 & 0 & 0 & 4 & 3 & 4 & 4 \\
& $33.33 \%$ & $100 \%$ & $0 \%$ & NA & $66.67 \%$ & $75.00 \%$ & $66.67 \%$ & $100 \%$ \\
DES & 1 & 0 & 2 & 0 & 1 & 1 & 1 & 1 \\
& $16.67 \%$ & $0 \%$ & $33.33 \%$ & $0 \%$ & $16.67 \%$ & $100 \%$ & $16.67 \%$ & $100 \%$ \\
\hline
\end{tabular}

The first row in each group indicates the number of mice and the second row indicates the percent change.

*The copulation rate was calculated as the number of copulated females per the number of total females used $\times 100$. The pregnancy rate was calculated as the number of pregnant females per the number of total females used $\times 100$. NA=not available.

Table 2. Numbers of offspring mothered by female mice treated with 0,10 or $100 \mathrm{mg} / \mathrm{kg} \mathrm{BW} /$ day of Pueraria mirifica (PM-0, PM-10 and PM-100, respectively) or $200 \mu \mathrm{g} / \mathrm{kg}$ BW/day of diethylstilbestrol (DES)

\begin{tabular}{lcccc}
\hline Group & $\begin{array}{c}\text { At } 4 \text { weeks during } \\
\text { the treatment period }\end{array}$ & $\begin{array}{c}\text { At } 8 \text { weeks during } \\
\text { the treatment period }\end{array}$ & $\begin{array}{c}\text { At } 4 \text { weeks during } \\
\text { the post-treatment period }\end{array}$ & $\begin{array}{c}\text { At } 8 \text { weeks during } \\
\text { the post-treatment period }\end{array}$ \\
\hline PM-0 & $11.0 \pm 1.6$ & 10 & $8.7 \pm 3.1$ & $9.4 \pm 2.5$ \\
PM-10 & $10.8 \pm 2.0$ & $10.0 \pm 2.6$ & $11.3 \pm 2.7$ & $10.7 \pm 2.2$ \\
PM-100 & $8.5(8,9)$ & 0 & $8.8 \pm 2.4$ & $8.5 \pm 1.3$ \\
DES & 0 & 0 & 3 & 5 \\
\hline
\end{tabular}

Numbers of offspring are expressed as means \pm SEM, if there were more than three treated females that gave birth.

Table 3. Relative organ weights of 50-day-old offspring mothered by female mice treated with $0,10 \mathrm{or} 100 \mathrm{mg} /$ $\mathrm{kg}$ BW/day of Pueraria mirifica (PM-0, PM-10 and PM-100, respectively) or $200 \mu \mathrm{g} / \mathrm{kg}$ BW/day of diethylstilbestrol (DES)

\begin{tabular}{lcccc}
\hline Relative organ weight & PM-0 & PM-10 & PM-100 & DES \\
\hline No. of female offspring & 35 & 40 & 37 & 3 \\
BW of female offspring & $31.89 \pm 0.44$ & $32.28 \pm 0.41$ & $31.69 \pm 0.37$ & $32.92 \pm 0.37$ \\
Uterus (mg/g) & $6.086 \pm 0.025$ & $5.422 \pm 0.015$ & $5.094 \pm 0.021$ & $4.698 \pm 0.104$ \\
Ovary (mg/g) & $0.751 \pm 0.009$ & $0.724 \pm 0.011$ & $0.753 \pm 0.013$ & $0.665 \pm 0.006$ \\
No. of male offspring & 32 & 40 & 37 & 5 \\
BW of male offspring & $35.64 \pm 1.00$ & $36.27 \pm 0.85$ & $36.46 \pm 0.72$ & $37.10 \pm 0.85$ \\
Testis (mg/g) & $7.321 \pm 0.014$ & $7.153 \pm 0.011$ & $7.244 \pm 0.012$ & $6.509 \pm 0.019$ \\
Epididymis (mg/g) & $2.353 \pm 0.011$ & $2.415 \pm 0.009$ & $2.362 \pm 0.011$ & $2.571 \pm 0.014$ \\
Seminal vesicle (mg/g) & $6.382 \pm 0.008$ & $6.194 \pm 0.010$ & $6.515 \pm 0.024$ & $5.929 \pm 0.019$ \\
\hline
\end{tabular}

Data are expressed as means \pm SEM.

tes, epididymides and seminal vesicles of the male pups mothered by the PM- and DES-treated mice were not significantly different from those of pups mothered by PM-0-treated mice (Table 3). The gross morphology of these reproductive organs was also normal. 


\section{Discussion}

The tuberous root of PM contains many active phytoestrogen compounds, and its estrogenic activity has been shown in animal experiments and clinical trials $[7-9,13,20]$. Previous studies have practically verified pronounced estrogenic activity in rodents using uterotropic and vaginal cornification assays $[3,7,8]$. Despite the fact no changes were observed in the uterine weights of intact mice after treatment with PM-100 in the present study, vaginal cornification occurred as early as the second day and persistent estrus was maintained throughout the treatment period. In contrast, it has been reported that treatment of ovariectomized rats with PM-100 significantly increases uterine weight $[7,8]$. One explanation for this difference is that ovariectomy lowered the level of endogenous estrogens in the rats and increased the sensitivity of their uterine response to phytoestrogen treatment compared with the intact mice in our study. Although no changes in organ weights were found, observation at the cellular level by histological study showed that there was high proliferation of the uterine endometrium in the PM-100 group compared with the PM-0 group. Our results are in agreement with a previous study reporting that the uterine weights of immature female mice administered subcutaneous injections of narigenin and biochanin A do not increase, although uterine epithelial cell height does increase [21]. Ashby et al. [22] and Tinwell et al. [23] showed that the uterotropic effect of coumestrol results from both an increase in uterine fluid content and hyperplasia of the endometrium. Rats treated with coumestrol exhibit a rise in uterine DNA content that mimics that of the estradiol effect [24-26]. The present results clearly indicated that the PM-100 has an estrogenic effect and that it acts directly on uterus; however, the changes in the uterus at the cellular levels were not high enough to increase uterine weight. The mechanism of action is probably through estrogen receptors in endometrium cells $[27,28]$.

Similarly, the ovaries of the PM-treated mice exhibited clear edema of the interstitial tissues, and their ovarian weights were unchanged. Furthermore, histological analyses of ovarian tissues indicated a decrease in ovarian folliculogenesis, that is, a reduction in primary, secondary and Graafian follicles. FSH and LH are key drivers of the mechanism of follicular development [29]. LH is essential for the final growth of antral follicles, and FSH stimulates small growing follicles. FSH together with insulin-like growth factor-I (IGF-I) and estradiol stimulate proliferation and differentiation of granulosa cells $[30,31]$. The results of a previous study showed that a dose of $100 \mathrm{mg} / \mathrm{kg}$ $\mathrm{BW} /$ day of PM orally administered to ovariectomized rats can reduce the elevation of circulating FSH and LH levels [7]. In the present study, treatment with PM-100 maintained lower levels of FSH and LH than treatment with PM-0. Therefore, arrest of follicular development may have occurred.

The present results clearly demonstrated that long-term exposure to PM-100 induced adverse effects on female mice fertility. That is, the PM-100treated mice exhibited persistent estrous, and their subsequent mating efficiency after treatment for 4 weeks was partially reduced; it was completely inhibited by treatment for 8 weeks. These results suggest that treatment with PM-100 affects the estrous cycle and mating behavior of female mice and subsequently results in reduced pregnancy rates and litter sizes. Previous studies have shown that treatment with soy supplement and tamoxifen (antiestrogen) suppresses lordosis in estrogen- and progesterone-primed female rats [32-35]. As mentioned above, treatment with PM-100 reduced the serum FSH and LH levels of the mice, and we suspected that there was a subsequent reduction in the estrogen level, although we did not determine the level of this hormone in the current study. Observation of reductions in the numbers of primary, secondary and Graaffian follicles in the ovaries of the PM-100 group support this hypothesis. However, reductions in reproductive efficiency recovered as early as 4 weeks after PM-100 withdrawal. On the other hand, reproductive impairments lasted for 8 weeks after DES withdrawal. Although the DES-treated mice exhibited complete recovery of reduced gonadotropin levels and alterations of their uteri and ovaries, only one of the mice accepted mating from a male mouse and produced offspring. Our previous study also demonstrated that recovery of the vaginal cytology of rats after receiving a synthetic estrogen, estradiol valerate, is slower than for those receiving PM containing phytoestrogens. One explanation for this is that phytoestrogens exhibit less binding affinity to both ER $\alpha$ and $\beta$, which can be found in large quan- 
tities in reproductive organs, whereas synthetic estrogens exhibit high binding affinity [27, 28]. A previous study concluded that this was an advantage of use of a phytoestrogen-rich herb for hormone replacement therapy compared with synthetic estrogens when a short-term effect is needed [8]. However, no abnormalities were observed in the external morphologies and reproductive organ weights of the 50-day-old offspring from the PMand DES-treated mice, which was in agreement with previous reports concerning other phytoestrogens [36, 37].

In conclusion, long-term exposure to $100 \mathrm{mg} / \mathrm{kg}$ BW of PM has adverse effects on mating efficiency and reproduction in adult female mice, whereas administration of $10 \mathrm{mg} / \mathrm{kg}$ BW of PM to rats does not induce any changes in the hypothalamic-pituitary-ovarian-uterine axis [8,9]. However, impairment of mating efficiency and reproduction after treatment with PM recovered faster than after treatment with synthetic estrogen. Thus, the present results suggest that a dosage of $100 \mathrm{mg} / \mathrm{kg}$ BW of PM, which has been reported to have no effect on hematological and biochemical parameters and has been suggested to be safe for human consumption on a kg BW basis, can induce reproductive impairments after long-term treatment. The dosage and duration of PM exposure must be considered depending on the purpose of usage.

\section{Acknowledgments}

We are grateful to Dr. A. F. Parlow and the Rat Pituitary Hormone Distribution Program (NIDDK, $\mathrm{NIH}$, Torrance, CA, USA) for providing RIA materials. This study was supported in part by the Inter-department of Physiology, Faculty of Graduate School, Chulalongkorn University, a grant for the Primate Research Unit, Chulalongkorn University, and Grants-in-Aid for Scientific Research (The $21^{\text {st }}$ Century Center of Excellence Program, E-1) from the Ministry of Education, Culture, Sports, Science and Technology of Japan and B-18310044 and the Japan Thailand Joint Research from the Japan Society for the Promotion of Science.

\section{References}

1. Chivapat $\mathbf{S}$, Chavalittumrong $\mathbf{P}$, Rattanajarasroj $\mathbf{S}$, Chuthaputti A, Panyamang S. Toxicity study of Pueraria mirifica Airy Shaw et Suvatabandhu. Bull Med Sci 2000; 42: 202-223 (in Thai with English abstract).

2. Kashemsanta MLC, Suvatabhandu K, Airy SHK. A new species of Pueraria (Leguminosae) from Thailand yielding an oestrogenic principle. Kew Bulletin 1952; 263-266.

3. Pope GS, Grundy HM, Jones HEH, Tait SAS. The estrogenic substance (miroestrol) from the tuberous roots of Pueraria mirifica. J Endocrinol 1958; 17: 15-16.

4. Chansakaow S, Sekine TIK, Okada M, Higuchi Y, Kudo M, Chaichantipyuth C. Identification of deoxymiroestrol as the actual rejuvenating principle of "Kwao Keur", Pueraria mirifica. The known miroestrol may be an artifact. J Nat Prod 2000; 63: 173-175.

5. Chansakaow S, Sekine TIK, Okada M, Higuchi Y, Kudo M, Chaichantipyuth C. Isoflavanoids from Pueraria minifica and their estrogenic activity. Planta Med 2000; 66: 572-575.

6. Benson GK, Cowie AT, Hosking ZD. Mammogenic activity of miroestrol. J Endocrinol 1961; 21: 401-409.

7. Malaivijitnond S, Kiatthaipipat $\mathbf{P}$, Cherdshewasart W, Watanabe G, Taya K. Different effects of Pueraria mirifica, a herb containing phytoestrogens, on
LH and FSH secretion in gonadectomized female and male rats. J Pharmacol Sci 2004; 96: 428-435.

8. Malaivijitnond S, Chansri K, Kijkuokool P, Urasopon $\mathbf{N}$, Cherdshewasart $\mathbf{W}$. Using vaginal cytology to assess the estrogenic activity of phytoestrogenrich herb. J Ethnopharmacol 2006; 107: 354-360.

9. Trisomboon H, Malaivijitnond S, Watanabe G, Taya K. Estrogenic effects of Pueraria mirifica on the menstrual cycle and hormone-related ovarian functions in cyclic female cynomolgus monkeys. J Pharmacol Sci 2004; 94: 51-59.

10. Trisomboon $\mathbf{H}$, Malaivijitnond S, Watanabe G, Taya K. Ovulation block by Pueraria mirifica: a study of its endocrinological effect in female monkeys. Endocrine 2005; 26: 33-39.

11. Trisomboon $\mathbf{H}$, Malaivijitnond S, Watanabe G, Cherdshewasart $\mathbf{W}$, Taya $K$. The estrogenic effect of Pueraria mirifica on gonadotropin levels in aged monkeys. Endocrine 2006; 1: 129-134.

12. Trisomboon $\mathbf{H}$, Malaivijitnond $\mathbf{S}$, Cherdshewasart W, Watanabe G, Taya K. Assessment of urinary gonadotropin and steroid hormone profiles of female cynomolgus monkeys after treatment with Pueraria mirifica herb. J Reprod Dev 2007; 53: 395-403.

13. Muangman $\mathbf{V}$, Cherdshewasart $\mathbf{W}$. Clinical trails of the phytoestrogen-rich herb, Pueraria mirifica, as a crude drug in the treatment of symptoms in meno- 
pausal women. Siriraj Hosp Gaz 2001; 53: 300-309 (in Thai with English abstract).

14. Cherdshewasart W. Toxicity tests of a phytoestrogen-rich herb, Pueraria mirifica. J Sci Res Chula Univ 2003; 28: 1-12.

15. Trisomboon $\mathbf{H}$, Malaivijitnond $\mathbf{S}$, Cherdshewasart W, Watanabe G, Taya K. Effect of Pueraria mirifica on the sexual skin coloration of aged menopausal cynomolgus monkeys. J Reprod Dev 2006; 52: 537542.

16. Saenphet K, Kantaloop P, Saenphet S, Aritajats S. Matagenicity of Pueraria mirifica Airy Shaw \& Suvatabandhu and antimutagenicity of Thunbergia laurifolia Linn. Southeast Asian J Trop Med Public Health 2005; 36: 238-241.

17. Korach KS, Metzler M, McLachlan JA. Estrogenic activity in vivo and in vitro of some diethylstilbestrol metabolites and analogs. Proc Natl Acad Sci USA 1978; 75: 468-471.

18. Gutendrof B, Westendorf J. Comparison of an array of in vitro assays for the assessment of the estrogenic potential of natural and synthetic estrogens, phytoestrogens and xenoestrogens. Toxicology 2001; 166: 79-89.

19. Jaroenporn S, Malaivijitnond S, Wattanasirmkit K, Trisomboon $H$, Watanabe G, Taya $K$, Cherdshewasart W. Effects of Pueraria mirifica, an herb containing phytoestrogens, on reproductive organs and fertility of adult male mice. Endocrine 2006; 30:93101.

20. Jones HEH, Pope GS. A study of the action of miroestrol and other oestrogenens on the reproductive tract of the immature female mouse. J Endocrine 1960; 20: 229-235.

21. Jefferson WN, Padilla-Banks E, Clark G, Newbold RR. Assessing estrogenic activity of phytochemicals using transcriptional activation and immature mouse uterotrophic responses. J Chromatogr B Analyt Technol Biomed Life Sci 2002; 777: 179-189.

22. Ashby J, Tinwell H, Soames AR, Foster JR. Induction of hyperplasia and increased DNA content in the uterus of immature rats exposed to coumestrol. Environ Health Perspect 1999; 107: 819-822.

23. Tinwell H, Soames AR, Foster JR, Ashby J. Estradiol-type activity of coumestrol in mature and immature ovariectomized rat uterotrophic assays. Environ Health Perspect 2000; 108: 631-634.

24. Whitten PL, Russell E, Naftolin F. Effects of a normal, human-concentration, phytoestrogen diet on rat uterine growth. Steroids 1992; 57: 98-106.

25. Santell RC, Chang YC, Nair MG, Helferich WG. Dietary genistein exerts estrogenic effects upon the uterus, mammary gland and the hypothalamic/ pituitary axis in rats. J Nutr 1997; 127: 263-269.

26. Gallo D, Cantelmo F, Distefano M, Ferlini C, Zannoni GF, Riva A, Morazzoni P, Bombardelli E, Mancuso S, Scambia G. Reproductive effects of dietary soy in female Wistar rats. Food Chem Toxicol 1999; 37: 493-502.

27. Kuiper GG, Carlsson B, Grandien K, Enmark E, Haggblad J, Nilsson S, Gustafsson JA. Comparison of the ligand binding specificity and transcript tissue distribution of estrogen receptor $\alpha$ and $\beta$. Endocrinology 1997; 138: 863-870.

28. Kuiper GG, Lemmen JG, Carlsson B, Corton JC, Safe SH, van der Saag PT, van der Burg B, Gustafsson JA. Interaction of estrogenic chemicals and phytoestrogens with estrogen receptor $\beta$. Endocrinology 1998; 139: 4252-4263.

29. Hadley ME. Hormones and female reproductive physiology. In: Endocrinology, $5^{\text {th }}$ ed. USA: Prentice-Hall; 2000: 445-472.

30. Khamsi F, Roberge S, Yavas Y, Lacanna IC, Zhu X, Wong J. Recent discoveries in physiology of insulinlike growth factor- 1 and its interaction with gonadotropins in folliculogenesis. Endocrine 2001; 16: 151-165.

31. Britt KL, Findlay JK. Estrogen actions in the ovary revisited. J Endocrinol 2002; 175: 269-276.

32. Etgan AM, Shamamian P. Regulation of estrogenstimulated lordosis behavior and hypothalamic progestin receptor induction by antiestrogens in female rats. Horm Behav 1986; 20: 166-180.

33. McKenna SE, Simon NG, Cologer-Clifford A. An assessment of agonist/antagonist effects of TAMOX in the female mouse brain. Horm Behav 1992; 26: 536544.

34. Patisaul HB, Dindo M, Whitten PL, Young LJ. Soy isoflavone supplements antagonize reproductive behavior and ER $\alpha$ - and ER $\beta$-dependent gene expression in the brain. Endocrinology 2001; 142: 2946-2952.

35. Patisaul HB, Luskin JR, Wilson ME. A soy supplement and tamoxifen inhibit sexual behavior in female rats. Horm Behav 2004; 45: 270-277.

36. Kang KS, Che JH, Lee YS. Lack of adverse effects in the F1 offspring maternally exposed to genistein at human intake dose level. Food Chem Toxicol 2002; 40: 43-51.

37. Fielden MR, Samy SM, Chou KC, Zacharewski TR. Effect of human dietary exposure levels of genistein during gestation and lactation on longterm reproductive development and sperm quality in mice. Food Chem Toxicol 2003; 41: 447-454. 